Check for updates

Cite this: RSC Adv., 2019, 9, 24105

\title{
Green electrochemical synthesis of silver sulfadiazine microcrystals
}

\author{
Faezeh Zivari Moshfegh, Mahmood Masoudi Khoram and Davood Nematollahi (D) * \\ Electrochemical synthesis of silver sulfadiazine (AgSD) microcrystals was carried out galvanostatically in a special \\ two-electrode cell equipped with a sacrificial silver rod anode and a stainless steel plate cathode. The cell used in \\ this work consists of a small cylindrical chamber containing aqueous sulfadiazine/sodium nitrate as the anode \\ compartment inside a larger cylindrical chamber containing nitric acid solution as the cathode compartment. \\ The ionic connection of two chambers is carried out through a solvent surface layer. In this study, the effect \\ of the experimental parameters such as applied current density and sodium nitrate concentration as well as \\ nitric acid concentration on the yield and energy consumption of AgSD is discussed. The proposed method is \\ fast and green and has unique features including synthesis in a single step, and no need for a metal salt.
}

Received 15th June 2019

Accepted 28th July 2019

DOI: $10.1039 / c 9 r a 04504 j$

rsc.li/rsc-advances

respectively, in its structure. It is also active against a wide range

\section{Introduction}

Electrochemical synthesis is a powerful technique for the synthesis of a broad spectrum of organic ${ }^{1-7}$ and inorganic compounds. ${ }^{8-14}$ In this way, electrochemical synthesis using sacrificial anodes is an interesting research field with a wide range of potential applications which has received much attention in recent years. ${ }^{15-18}$ One of the most important applications of sacrificial anodes is their use in the synthesis of metallic complexes. ${ }^{15}$ This method is fast, selective and has unique features including synthesis in a single step, possibility of synthesizing homoleptic and heteroleptic complexes, possibility of use of proligands which can be converted to ligands at the cathode and no need for a metal salt. In line with these studies one should also mention the valuable research studies of Tuck et al. in the synthesis of different types of metallic complexes using a variety of sacrificial anodes..$^{11,19-23}$ In addition, in recent years, many new metal complexes were synthesized using sacrificial anodes ${ }^{12}$ such as cobalt, ${ }^{24,25}$ nickel, ${ }^{24,25}$ zinc, ${ }^{24,25}$ cadmium, ${ }^{24,25}$ copper $^{24-26}$ and iron. ${ }^{27}$

On the other hand, the use of sulfonamides in the treatment of wounds and burns was common during World War II. ${ }^{28}$ AgSD was synthesized in 1960 and was used as the first silver sulfonamide to treat burns. ${ }^{29} \mathbf{A g S D}$ is a metal complex of sulfadiazine, that is widely used as an antibacterial agent for surface burns and wound treatments. ${ }^{30}$ It destroys the cell membrane and inhibits DNA replication and has a broadspectrum action against both Gram-positive and Gramnegative bacteria. ${ }^{31}$ These properties are due to the fact that AgSD has both oligodynamic properties and antibacterial activity due to the presence of silver ions and sulfadiazine,

Faculty of Chemistry, Bu-Ali-Sina University, Hamedan 65174, Iran. E-mail: nemat@ basu.ac.ir of micro-organisms. ${ }^{32}$ In addition, the proven efficacy of AgSD in the treatment of Pseudomonas infection in burns has been documented. ${ }^{33}$ In line with our research program in replacing traditional synthetic methods by electrochemical methods ${ }^{1-7,17}$ herein, we would like to report an efficient electrochemical method for the synthesis of AgSD microcrystals through oxidation of a silver rod in the presence of sulfadiazine in aqueous solution and in a simple quasi-two-compartment cell.

\section{Results and discussion}

\section{Voltammetric studies}

This study was performed in order to investigate the reactivity of anodically generated silver ions in the reaction with sulfadiazine. Fig. 1a shows the cyclic voltammogram of silver electrode.

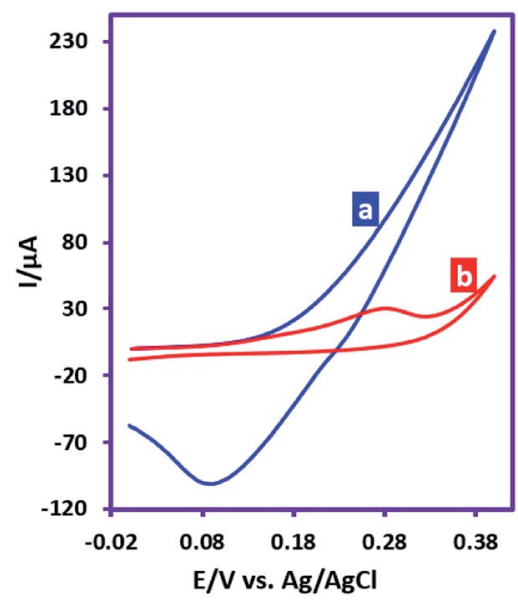

Fig. 1 Cyclic voltammograms of silver electrode (area, $1.8 \mathrm{~mm}^{2}$ ), (a) in the absence and $(b)$ in the presence of sulfadiazine $(10 \mathrm{mM})$. Scan rate: $100 \mathrm{mV} \mathrm{s}^{-1}$. Temperature: $25 \pm 1{ }^{\circ} \mathrm{C}$. 
The CV shows an anodic current in positive going scan corresponds to the generation of silver ions and a cathodic counterpart peak in the negative-going scan which corresponds to the reduction of silver ions. Fig. $1 \mathrm{~b}$ shows the cyclic voltammogram of silver electrode in the presence of sulfadiazine. As can be seen, the cathodic peak observed in CV 1a is omitted. This phenomenon proves the reaction of silver ions with sulfadiazine and the lack of silver ions at the electrode surface.

\section{Mechanistic studies}

By applying current to the cell, the generation of silver ion and its reaction with sulfadiazine are carried out, which results in the formation of a white AgSD precipitate in the anode compartment. In fact, the nature of this reaction is an ion exchange reaction in which sodium ion is replaced by silver ion. ${ }^{34-36}$ Under these conditions, the cathodic reaction is the reduction of water and formation of hydroxide ion, which is neutralized by the nitric acid present in the cathode compartment (Scheme 1). The use of a two-compartment cell with electrolytes of different $\mathrm{pH}$, does not permit the generation of silver oxide or inactivation sulfadiazine. Increasing $\mathrm{pH}$ during electrolysis in non-acidic solutions causes the formation of silver oxide. On the other hand, protonation of sulfadiazine and consequently its inactivation, prevents its complexation with silver ions. So we came to the conclusion that a quazi-two-compartment cell was to be used.

\section{Current-potential relationship and energy consumption}

The non-steady-state linear current-potential relationship for the synthesis of AgSD is shown in Fig. 2. The slope of the line is a measure of cell conductivity and shows that in electrochemical synthesis of AgSD, an ohmic controlled process is

$$
\begin{array}{ll}
\text { Anodic reaction: } & \mathrm{Ag}-\mathrm{e}^{-} \longrightarrow \mathrm{Ag}^{+} \\
\text {Anodic compartment reaction: } & \mathrm{Ag}^{+}+\mathrm{SD}^{-} \longrightarrow \mathrm{AgSD} \\
\text { Cathodic reaction: } & \mathrm{H}_{2} \mathrm{O}+2 \mathrm{e}^{-} \longrightarrow \mathrm{H}_{2}+2 \mathrm{OH}^{-} \\
\text {Cathodic compartment reaction: } & 2 \mathrm{OH}^{-}+2 \mathrm{H}^{+} \longrightarrow 2 \mathrm{H}_{2} \mathrm{O}
\end{array}
$$

Scheme 1 Reaction mechanism for electrochemical synthesis of AgSD.

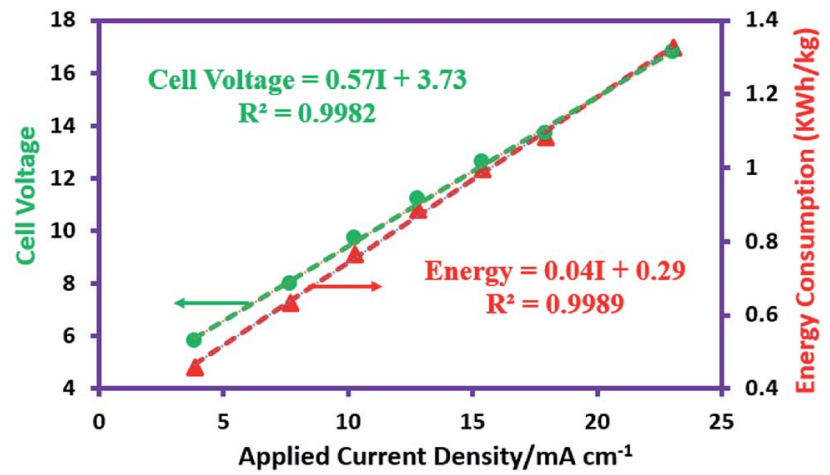

Fig. 2 Variation of cell voltage and energy consumption with the current density. taking place. On the other hand, the electrical energy consumption is an important parameter in electrochemical reactions for energy saving processes and process development. The energy consumption for the electrochemical synthesis of AgSD is calculated using the following equations: ${ }^{38}$

$$
\text { Energy consumption }=\frac{n F E_{\text {cell }}}{3.6 \times 10^{4} \phi M}
$$

where, $n$ is the number of transferred electrons, $F$ is the Faraday constant (96 $485 \mathrm{C} \mathrm{mol}^{-1}$ ), $E_{\text {cell }}$ is cell voltage (V), $M$ is molecular weight of AgSD $\left(\mathrm{C}_{10} \mathrm{H}_{9} \mathrm{AgN}_{4} \mathrm{O}_{2} \mathrm{~S}\right)\left(357.14 \mathrm{~g} \mathrm{~mol}^{-1}\right)$ and $\phi$ is current efficiency which is determined as follows: ${ }^{37}$

Current efficiency $=\frac{\text { charge used in forming product }}{\text { total charge }} \times 100$

Electrical energy consumption depends on the cell voltage, so that, as the current density rises, the energy consumption increases linearly. An increase in the current density causes a linear increase in the ohmic voltage and this increasing voltage in turn causes an increase in the energy consumption (Fig. 2).

\section{Optimization of effective parameters}

Here, the parameters influencing on product yield and energy consumption, including current density, amount of electricity, sodium nitrate and nitric acid concentration have been studied by one factor at the time method to find the best condition. The applied current density is one of the most important parameter affecting the product yield, energy consumption (see previous section) and the size of AgSD crystals. For this purpose, different current densities were applied, ranging from 3.75 to $22.5 \mathrm{~mA}$ $\mathrm{cm}^{-2}$ (15 to $90 \mathrm{~mA}$ ) keeping the electricity consumed constant and the yield of the silver sulfadiazine was calculated. The results of these experiments show that the studied current densities have no significant effects on the yield of AgSD, so in all experiments the yield was $97 \pm 2 \%$. Our data also show that there is a linear relationship between the amount of electricity consumed and the yield of AgSD, so that for example, doubling of the electricity consumption doubles the yield of AgSD.

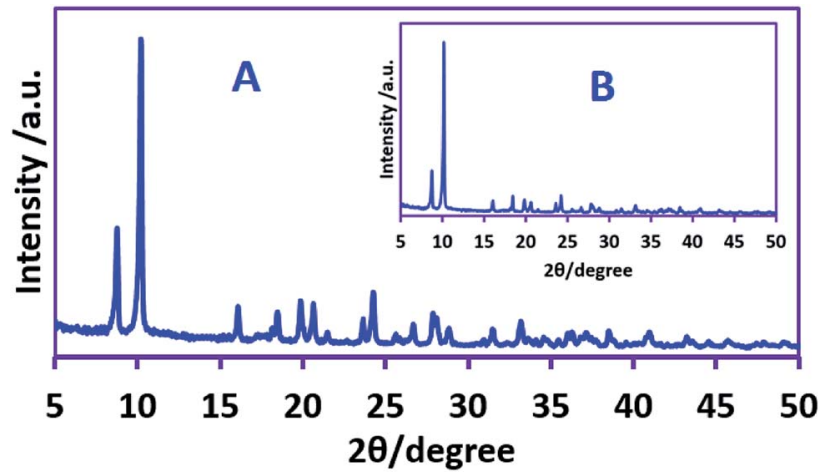

Fig. 3 XRD patterns of the AgSD synthesized at applied current density of: (A) $62.5 \mathrm{~mA} \mathrm{~cm}^{-2}$ and (B) $12.5 \mathrm{~mA} \mathrm{~cm}^{-2}$. 
Another important effect of current density, is its effect on the size of AgSD crystals. Fig. 3 shows the XRD patterns of AgSD synthesized at $12.5 \mathrm{~mA} \mathrm{~cm}{ }^{-2}(50 \mathrm{~mA})$ and $62.5 \mathrm{~mA} \mathrm{~cm}{ }^{-2}(250$ $\mathrm{mA}$ ) current densities. The peaks and peak positions are in good agreement with the known XRD data for AgSD. ${ }^{32,38-41}$ The average size of the crystalline particles synthesized at the applied current, $50 \mathrm{~mA}\left(12.5 \mathrm{~mA} \mathrm{~cm}^{-2}\right)$ was obtained using the Scherrer's formula yield value of 0.26 micrometer $(\mu \mathrm{m})$. However, by increasing the applied current to $250 \mathrm{~mA}(62.5 \mathrm{~mA}$ $\mathrm{cm}^{-2}$ ), the size of AgSD crystals decreases to $0.15 \mu \mathrm{m}$. These results confirm that the size of AgSD crystals can be controlled by controlling the applied current density.

The effect of sodium nitrate concentration on product yield and energy consumption was investigated. For this purpose, the sodium nitrate concentration varied from $0.018 \mathrm{M}(0.025 \mathrm{gr})$ to $0.123 \mathrm{M}(0.168 \mathrm{gr})$ while the other parameters (temperature $=$ $298 \mathrm{~K}$, charge consumed $=18 \mathrm{C}$, sodium sulfadiazine concentration $=0.18 \mathrm{mmol}(0.05 \mathrm{~g})$, nitric acid concentration $=0.05 \mathrm{M}$ and applied current $=50 \mathrm{~mA}$ ) are kept constant. Our data show that changes in sodium nitrate concentration do not have significant effect on the yield of AgSD. However, Fig. 4 displays the effect of sodium nitrate concentration on the energy consumption in AgSD synthesis. As can be seen, energy consumption decreased markedly with increasing concentration of sodium nitrate. This phenomenon is interpreted as follows: an increase in the sodium nitrate concentration causes a decrease in the ohmic voltage and this decreasing voltage in turn causes a decrease in the energy consumption (Fig. 4). With regard to the variation in energy consumption, the sodium nitrate concentration $0.062 \mathrm{M}(0.084 \mathrm{gr})$ was selected as the optimum sodium nitrate concentration in AgSD synthesis.

The nitric acid in cathodic compartment was used as both supporting electrolyte and for preventing $\mathrm{pH}$ rise. Therefore, the nitric acid concentration is effective on the energy consumption and should be investigated. For this purpose, the nitric acid concentration varied from 0.01 to $0.1 \mathrm{M}$, while the other parameters (temperature $=298 \mathrm{~K}$, charge consumed $=18 \mathrm{C}$, sodium sulfadiazine concentration $=0.18 \mathrm{mmol}(0.05 \mathrm{~g})$, sodium nitrate concentration $=0.062 \mathrm{M}$ and applied current $=$

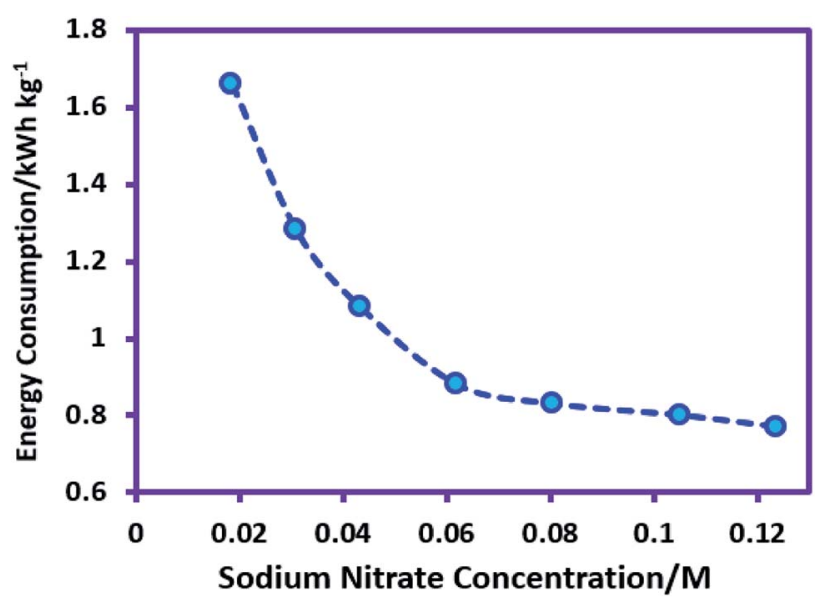

Fig. 4 Variation of energy consumption with the sodium nitrate concentration.

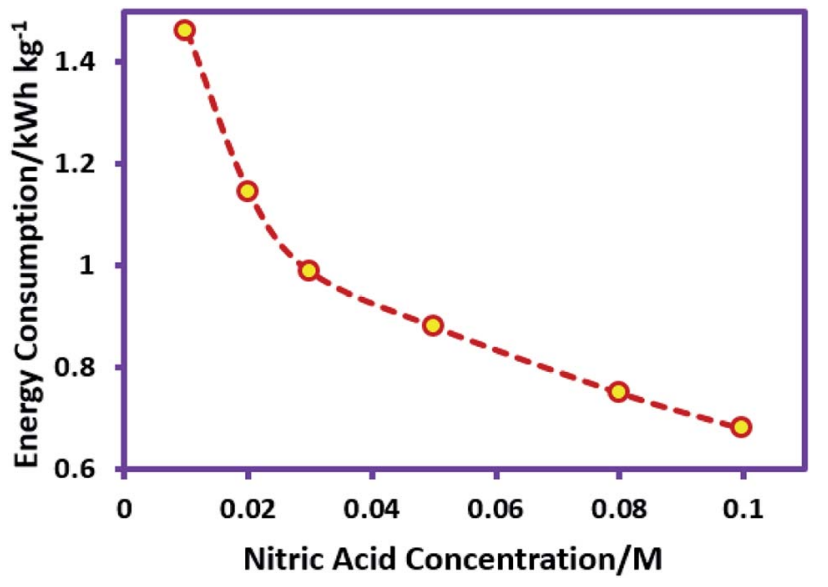

Fig. 5 Variation of energy consumption with the nitric acid concentration.

$50 \mathrm{~mA}$ ) are kept constant. Fig. 5 shows the effect of nitric acid concentration on the energy consumption in AgSD synthesis.

In accordance with Fig. 5, by increasing the nitric acid concentration, energy consumption decreases due to decrease in ohmic resistance. On the other hand, when the concentration of acid in the cathode compartment is increased, the sulfadiazine ions in the anode compartment start to protonate disabling
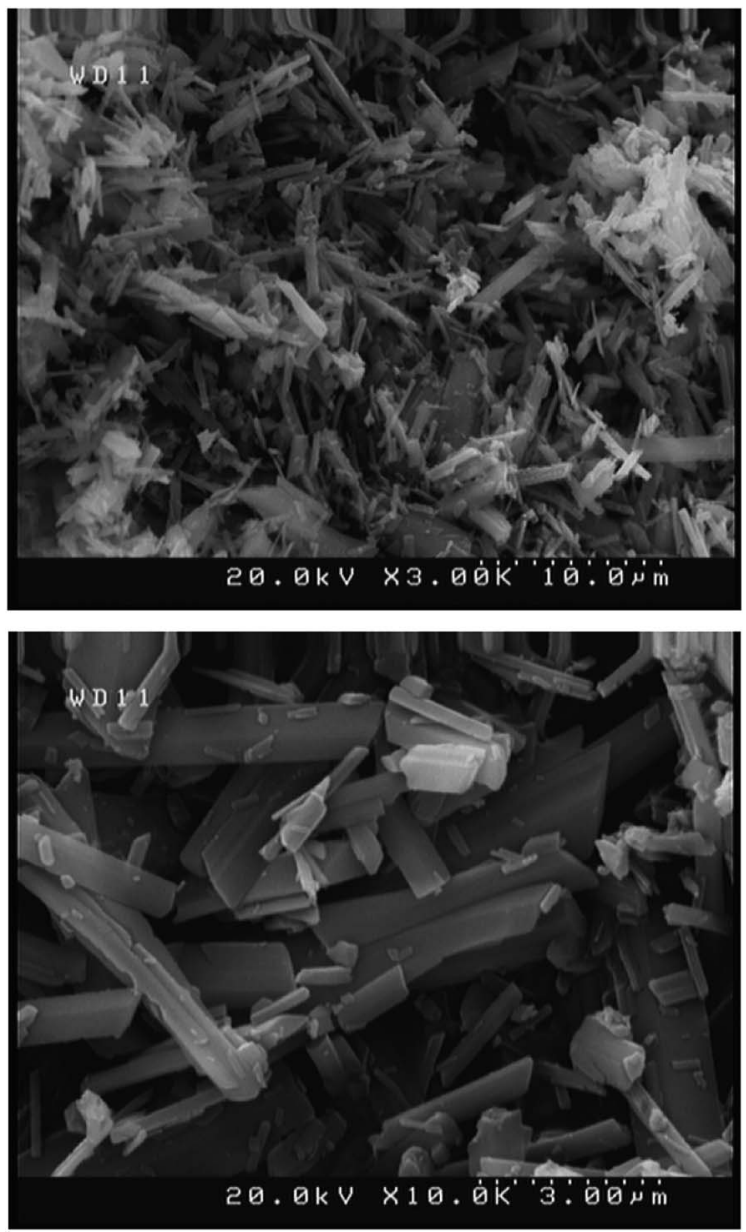

Fig. 6 FE-SEM images of synthesized silver sulfadiazine. 


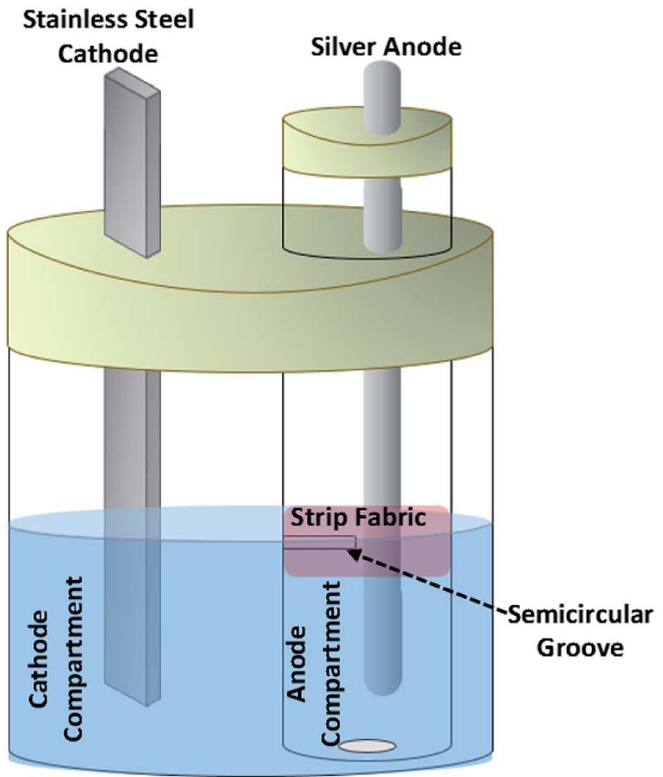

Fig. 7 The cell used in the synthesis of AgSD.

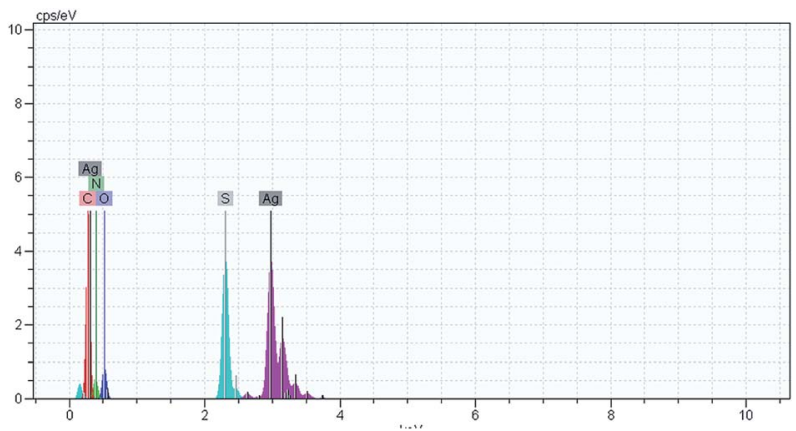

Fig. 8 EDS spectrum of as synthesized silver sulfadiazine.

the formation of AgSD. With regard to these data, the nitric acid concentration 0.05 $\mathrm{M}$ was selected as the optimum nitric acid concentration in AgSD synthesis. It should be noted that changes in nitric acid concentration, such as sodium nitrate do not have significant effect on the yield of AgSD.

The synthesized silver sulfadiazine under optimized conditions was studied by FE-SEM to evaluate the morphology and size of the AgSD particles (Fig. 6). This figure shows that the silver sulfadiazine crystals are in micro size and rectangular shape cube. $^{42}$ The antibacterial effect of AgSD is limited by its low solubility in water. ${ }^{43}$ On the other hand, it has been made clear that, AgSD nanocrystals aggravate the cytotoxicity. ${ }^{44}$ These points limit topical therapeutic effects of silver sulfadiazine to a large extend. ${ }^{\mathbf{4 4}}$ Therefore, we think that the AgSD microstructures will have the highest efficiency for topical burn therapy.

\section{Conclusions}

We describe in this research the electrochemical synthesis of silver sulfadiazine microcrystals based on using a simple quasi-twocompartment cell equipped with an $\mathrm{Ag}$ rod as sacrificial anode and stainless steel cathode for the first time. The advantages of the method, such as high and pure yield, use of common electrodes, use of water as solvent, use of metal instead of expensive metal salt, no need for oxidizing or reducing agents, low reaction time and low energy consumption were observed. In addition, in this method, the size of AgSD crystals can be easily controlled by controlling the applied current density. This technique is environmentally-friendly and easy to scale-up to synthesize silver sulfadiazine.

\section{Experimental section}

\section{General remarks}

Electrochemical synthesis of AgSD was carried out in galvanostatic conditions using a Dazheng DC Power Supply PS-303D, China, in a quasi-two-compartment cell equipped with a sacrificial silver anode and a stainless steel cathode. Fourier transmission infrared spectrum (FT-IR) in KBr was done using a PerkinElmer Spectrum GX spectrometer. The HITACHI S-4160 apparatus was employed for the recording of field-emission scanning electron microscopy (FESEM) images. Melting point was recorded using Barnstead Electrothermal instrument. Micro-compositional analysis of the AgSD was done by energy dispersive spectroscopy (EDS, Rontec). X-ray diffraction (XRD) tests of the AgSD was done by a Panalytical X'pert PRO diffractometer. An Autolab model PGSTAT 30 potentiostat/galvanostat was used for cyclic voltammetry. Sodium sulfadiazine (NaSD), nitric acid and sodium nitrate were purchased from Sigma-Aldrich and used without further purification.

\section{Cell design}

The cell used in this work consists of a small cylindrical chamber ( $2.5 \mathrm{~cm}$ diameter) equipped with a sacrificial silver rod anode containing aqueous sodium sulfadiazine and sodium nitrate as the anode compartment inside a larger cylindrical chamber as the cathode compartment equipped with a stainless steel sheet cathode containing nitric acid solution (Fig. 7). The ionic connection of two chambers is carried out through a solvent surface layer. For this purpose, a semicircular groove was made on the anode compartment at the solvent surface layer ( $4 \mathrm{~cm}$ from the bottom). For more separation between anolyte and catholyte solutions, a strip of ordinary fabric as barrier is placed on the groove (Fig. 7).

\section{Electrochemical synthesis of silver sulfadiazine}

The quasi-two compartment cell shown in Fig. 7 is used for electrochemical synthesis of AgSD. A water (16 mL) containing sodium sulfadiazine $(0.18 \mathrm{mmol})$ ( $0.05 \mathrm{~g})$ and sodium nitrate (1 $\mathrm{mmol})(0.085 \mathrm{~g})$ was added to anode compartment. An aqueous nitric acid (0.05 M) (45 mL) was added to cathode compartment. Under these conditions, the solution level in the two compartments is the same. The cell was subjected to electrolysis by applying a current density of $12.5 \mathrm{~mA} \mathrm{~cm}^{-2}$ (or $50 \mathrm{~mA}$ ) for $6 \mathrm{~min}$. At the end of electrolysis, a solid white precipitate was formed which was collected by filtration and was rinsed with deionized water several times until the eluate is free of silver ions. After drying in oven at $100{ }^{\circ} \mathrm{C}$ for $6 \mathrm{~h}$, the obtained white powder was subjected to characterization by melting point, FT-IR and EDS 
spectroscopy. Melting point: 285-287 ${ }^{\circ} \mathrm{C}$ [lit. 35 286-288 ${ }^{\circ} \mathrm{C}$ ]. Yield: 97\%. FT-IR $(\mathrm{KBr})$ : 555, 586, 735, 839, 977, 1077, 1136, 1233, 1424, 1502, 1552, 1583, 1598, 1654, 3076, 3119, 3262, 3444, 3391. ${ }^{41}$ The EDS spectrum of AgSD is shown in Fig. 8. This spectrum only contains $\mathrm{Ag}, \mathrm{S}, \mathrm{O}, \mathrm{C}$ and $\mathrm{N}$ elements.

\section{Conflicts of interest}

The authors declare no conflict of interest.

\section{Acknowledgements}

The authors wish to acknowledge Iran National Science Foundation (INSF) for financial support of this work. The authors also acknowledge the Bu-Ali Sina University Research Council and Center of Excellence in Development of Environmentally Friendly Methods for Chemical Synthesis (CEDEFMCS) for their support of this work.

\section{Notes and references}

1 S. Momeni and D. Nematollahi, Green Chem., 2018, 20, 4036. 2 B. Mokhtari, D. Nematollahi and H. Salehzadeh, Green Chem., 2018, 20, 1499.

3 M. Jamshidi and D. Nematollahi, ACS Sustainable Chem. Eng., 2017, 5, 9423.

4 A. Maleki, D. Nematollahi, F. Rasuli and A. ZeinodiniMeimand, Green Chem., 2016, 18, 672.

5 E. Salahifar, D. Nematollahi, M. Bayat, A. Mahyari and H. Amiri Rudbari, Org. Lett., 2015, 17, 4666.

6 D. Habibi, N. Pakravan and D. Nematollahi, J. Electroanal. Chem., 2015, 759, 190.

7 D. Nematollahi, M. S. Workentin and E. Tammari, Chem. Commun., 2006, 1631.

8 Molecular Electrochemistry of Inorganic, Bioinorganic and Organometallic Compounds, ed. A. J. L. Pombeiro and J. A. McCleverty, Springer, 1993.

9 C. Puente and I. López, in Direct Synthesis of Metal Complexes, Elsevier, 2018, pp. 87-141.

10 A. D. Garnovskii, L. M. Blanco, B. I. Kharisov, D. A. Garnovskii and A. S. Burlov, J. Coord. Chem., 1999, 48, 219.

11 D. G. Tuck, Pure Appl. Chem., 1979, 51, 2005.

12 A. M. Vecchio-Sadus, J. Appl. Electrochem., 1993, 23, 401.

13 M. C. Chakravorti and G. V. Subrahmanyam, Coord. Chem. Rev., 1994, 135, 65.

$14 \mathrm{~N}$. Ibl, and H. Vogt, in Inorganic electrosynthesis, ed. J. O'M. Bockris, B. E. Conway, E. Yeager and R. E. White, Springer, Boston, 1981, pp. 167-250.

15 A. Rodríguez and J. A. García-Vázquez, Coord. Chem. Rev., 2015, 303, 42.

16 E.-S. Z. El-Ashtoukhy, N. K. Amin, M. M. Abd El-Latif, D. G. Bassyouni and H. A. Hamad, J. Cleaner Prod., 2017, 167, 432.

17 S. Alizadeh and D. Nematollahi, J. Am. Chem. Soc., 2017, 139, 4753.
18 Y. Gao, W. Xu, B. Mason, K. D. Oakes and X. Zhang, Electrochim. Acta, 2017, 246, 707.

19 N. Kumar and D. G. Tuck, Inorg. Chem., 1983, 22, 1951.

20 J. L. Hencher, M. A. Khan, F. F. Said and D. G. Tuck, Polyhedron, 1985, 4, 1263.

21 J. L. Hencher, M. Khan, F. F. Said, R. Sieler and D. G. Tuck, Inorg. Chem., 1982, 21, 2787.

22 T. A. Annan, R. Kumar and D. G. Tuck, Inorg. Chem., 1990, 29, 2475.

23 R. Kumar, H. E. Mabrouk and D. G. Tuck, J. Chem. Soc., Dalton Trans., 1988, 0, 1045.

24 V. G. Vlasenko, D. A. Garnovskii, G. G. Aleksandrov, N. I. Makarova, S. I. Levchenkov, A. L. Trigub, Ya. V. Zubavichus, A. I. Uraev, Yu. V. Koshchienko and A. S. Burlov, Polyhedron, 2019, 157, 6.

25 I. Casanova, M. L. Durán, J. Viqueira, A. Sousa-Pedrares, F. Zani, J. A. Real and J. A. García-Vázquez, Dalton Trans., 2018, 47, 4325.

26 J. Viqueira, M. L. Durán, J. A. García-Vázquez, J. Castro, C. Platas-Iglesias, D. Esteban-Gómez, G. Alzuet-Piña, A. Moldes and O. R. Nascimento, New J. Chem., 2018, 42, 15170. 27 Y. Hong, L. Jarrige, K. Harms and E. Meggers, J. Am. Chem. Soc., 2019, 141, 4569.

28 C. L. Fox Jr, Arch. Surg., 1968, 96, 184.

29 A. T. M. Fiori, D. H. Nakahata, A. Cuin, W. R. Lustri and P. P. Corbi, Polyhedron, 2017, 121, 172.

30 A. C. Miller, R. M. Rashid, L. Falzon, E. M. Elamin and S. Zehtabchi, J. Am. Acad. Dermatol., 2012, 66, e159.

31 S. Hoffmann, Scand. J. Plast. Reconstr. Surg., 1984, 18, 119.

32 A. Bult, and C. M. Plug, Silver sulfadiazine, in Analytical Profiles of Drug Substances, Academic Press, 1984, vol. 13, pp. 553-571.

33 B. J. Sandmann, R. U. Nesbitt Jr and R. A. Sandmann, J. Pharm. Sci., 1974, 63, 948.

34 W. Wei, J. Wu, S. Cui, Y. Zhao, W. Chen and L. Mi, Nanoscale, 2019, 11, 6243.

35 W. Wei, S. Cui, L. Ding, L. Mi, W. Chen and X. Hu, ACS Appl. Mater. Interfaces, 2017, 9, 40655.

36 W. Wei, W. Chen, L. Ding, S. Cui and L. Mi, Nano Res., 2017, 10, 3726.

37 D. Pletcher, Industrial Electrochemistry, Springer-Science Business Media, 1984, p. 76.

38 X. Wen, Y. Zheng, J. Wu, L. Yue, C. Wang, J. Luan, Z. Wu and K. Wang, Prog. Nat. Sci.: Mater. Int., 2015, 25, 197.

39 J. Luan, J. Wu, Y. Zheng, W. Song, G. Wang, J. Guo and X. Ding, Biomed. Mater., 2012, 7, 065006.

40 M. Venkataraman and M. Nagarsenker, AAPS PharmSciTech, 2013, 14, 254.

41 K. S. Jodar, V. M. Balcao, M. V. Chaud, M. Tubino, V. M. Yoshida, J. M. Oliveira Jr and M. M. Vila, J. Pharm. Sci., 2015, 104, 2241.

42 A. M. Bowen, Microscope, 2009, 57, 11.

43 E. Dellera, M. C. Bonferoni, G. Sandri, S. Rossi, F. Ferrari, C. Del Fante, C. Perotti, P. Grisoli and C. Caramella, Eur. J. Pharm. Biopharm., 2014, 88, 643.

44 L. Gao, H. Gan, Z. Meng, R. Gu, Z. Wu, X. Zhu, W. Sun, J. Li, Y. Zheng, T. Sun and G. Dou, Colloids Surf., B, 2016, 148, 343. 